\title{
Estraga-prazeres feministas \\ (e outras sujeitas voluntariosas) $^{1}$
}

\author{
Feminist Killjoys \\ (And Other Willful Subjects)
}

\section{Sara Ahmed}

Estudiosa independente e escritora cujo foco passa por questões feministas, queer e raciais. Já foi professora em Lancaster University e Goldsmiths, University of London e professora visitante nas universidades de Cambridge (Inglaterra), Rutgers (EUA), Sidney e Adelaide (Austrália). É autora de uma dezena de livros, incluindo The Cultural Politics of Emotion (2004), Queer Phenomenology (2006), Willful Subjects (2014) e Living a Feminist Life (2017).

\section{Tradução:}

\section{Luiza Quental}

É formada em Cinema pela PUC-Rio, onde escreveu e dirigiu dois curta-metragens que passaram por diversos festivais nacionais e internacionais. Roteirista, escritora e pesquisadora, atualmente realiza Mestrado em Comunicação e Cultura pela Escola de Comunicação da Universidade Federal do Rio de Janeiro, com pesquisa sobre tecnologia e subjetividade.

Revisão: Liv Sovik

Submetido em 01 de Setembro de 2020 Aceito em 28 de Novembro de 2020

\section{RESUMO}

Questionando da figura da "estraga-prazeres feminista", este ensaio explora sua negatividade, bem como sua promessa de agência. Ao enquadrar o pensamento

\footnotetext{
${ }^{1}$ Publicado originalmente em AHMED, Sara. "Feminist Killjoys (And Other Willful Subjects)", S\&F Online (The Scholar and Feminist Online), Issue 8.3: Summer 2010.

http://sfonline.barnard.edu/polyphonic/ahmed_01.htm\#text1. Todos os direitos reservados.
} 
feminista como uma crítica da felicidade, sugere que a sujeita feminista deve ser entendida como uma "figura voluntariosa". A obstinação feminista é, assim, entendida como o terreno incerto para uma política coletiva de tradução de emoções individuais, dor ou raiva diante das injustiças. Além disso, a figura feminista voluntariosa pode ajudar a compreender as formas pelas quais, nos espaços feministas, as mulheres negras foram reduzidas à sua raiva e designadas como causadoras das divisões produzidas pelo racismo. A posição de obstinação é, portanto, tanto um lugar de tensões políticas quanto um lugar de reivindicações. PALAVRAS-CHAVE: feminismo; sexismo; racismo; emoções; produção da subjetividade

\section{ABSTRACT}

Questioning the figure of the "feminist killjoy", this essay explores its negativity, as well as its promise of agency. By framing feminist thought as a critique of happiness, it suggests that the feminist subject should be understood as a "willful subject". The feminist willfulness is thus understood as the uncertain ground for a collective politics translating individual emotions, the pain or anger felt in the face of injustices. Furthermore, the figure of the willful feminist subject may help understand the ways by which, within feminist spaces, black women have been reduced to their anger and designated as the cause of divisions produced by racism. The position of willfulness is therefore as much a place of political tensions as a place for political claims.

\section{KEYWORDS: feminism; sexism; racism; emotions; subjectivization}

Pode ser difícil lembrar de ter se tornado feminista, nem que seja porque é difícil lembrar de uma época em que você não se sentia assim. É possível ter sempre sido assim? É possível ter sido feminista desde o início? Uma história feminista pode ser um começo. Talvez possamos fazer sentido da complexidade do feminismo enquanto espaço ativista se pudermos produzir um relato de como o feminismo se torna um objeto afetivo, algo em que investimos, uma forma de nos relacionarmos com o mundo, uma forma de dar sentido a como nos relacionamos com o mundo. Quando "feminismo" se tornou uma palavra que não só falava para você, mas falava você, que falava de sua existência ou até mesmo falava de maneira a fazer você existir? 0 som da palavra, seu som? Como nos reunimos ao nos 
reunirmos em torno dessa palavra, unindo-nos ao aderir a ela? 0 que significou, o que significa, agarrar-se ao "feminismo", lutar sob seu nome; sentir em seus altos e baixos, suas idas e vindas, nossos próprios altos e baixos, nossas próprias idas e vindas?

Qual é a minha história? Como vocês, eu tenho muitas. Uma maneira de contar minha história feminista seria começar com uma mesa. Em torno da mesa, uma família se reúne. Sempre sentamos no mesmo lugar: meu pai numa cabeceira, eu na outra, minhas duas irmãs de um lado, minha mãe do outro. Sempre nos sentamos assim, como se estivéssemos tentando garantir mais do que o nosso lugar. Uma memória de infância, sim. Mas também é a memória de uma experiência cotidiana no sentido bastante literal de uma experiência que acontecia todos os dias. Um cotidiano intenso: meu pai fazendo perguntas, minhas irmãs e eu respondendo, minha mãe geralmente em silêncio. Quando a intensidade se transforma em tensão?

Começamos com uma mesa. Em torno desta mesa, a família se reúne, conversando educadamente, onde apenas alguns assuntos podem ser levantados. Alguém diz algo que você considera problemático. Você está ficando tensa; o clima está ficando tenso. Como é difícil saber a diferença entre o que é você e o que é! Você responde, com cuidado, talvez. Você diz por quê acha que o que foi dito é problemático. Você pode estar falando baixo, mas está começando a se sentir provocada, reconhecendo com frustração que está sendo provocada por alguém que está te provocando. Ao se colocar ou falar abertamente, você perturba a situação. 0 fato de você ter descrito o que foi dito por outra pessoa como um problema significa que você criou um problema. Você se transforma no problema que cria.

Ser objeto de desaprovação compartilhada, aqueles olhares que conseguem te cortar, te cortam da conversa. Uma experiência de alienação pode estilhaçar um mundo. A família se reúne ao redor da mesa; supõe-se que sejam ocasiões felizes. Como nos esforçamos para manter a ocasião feliz, para manter a superfície da mesa polida para que reflita uma boa imagem da família. Tanto que você não deve

\section{Dossiê Crise, Feminismo e Comunicação - https://revistaecopos.eco.ufrj.br/}

ISSN 2175-8689 - v. 23, n. 3, 2020

DOI: 10.29146/eco-pos.v23i3.27642 
dizer, fazer, ser, a fim de preservar essa imagem. Se você diz, faz ou é qualquer coisa que não reflita a imagem da família feliz de volta para si, o mundo fica distorcido. Você se torna a causa de uma distorção. Você é a distorção que causa. Outro jantar, arruinado. Alienar-se de uma imagem pode permitir que você veja o que essa imagem não reflete e não refletirá.

Tornar-se feminista pode ser uma alienação da felicidade (embora não só isso, não apenas isso: ah, a alegria de poder deixar o lugar que lhe foi dado!). Quando sentimos felicidade na proximidade dos objetos certos, estamos alinhadas; estamos no caminho certo. Você se torna alienada - desalinhada de uma comunidade afetiva - quando não experimenta a felicidade das coisas certas. A lacuna entre o valor afetivo de um objeto e como experimentamos um objeto pode envolver uma gama de afetos, que são direcionados pelos modos de explicação que oferecemos para preencher essa lacuna.

Se somos decepcionadas com algo que deveria nos fazer felizes, geramos explicações de por que aquela coisa é decepcionante. Podemos ficar desapontadas sem nunca sermos felizes. Pense no dia do casamento, imaginado como "o dia mais feliz da sua vida" antes mesmo de acontecer! O que acontece quando o dia acontece, se a felicidade não acontece? Em seu clássico "The Managed Heart", Arlie Russell Hochschild explora como, se a noiva não está feliz no dia do casamento e se sente "deprimida e chateada", ela está experimentando um "afeto inadequado" ou sendo afetada de maneira inadequada. É preciso salvar o dia sentindo-se bem: "percebendo uma lacuna entre o sentimento ideal e o sentimento real que tolerava, a noiva se impele a ser feliz." [2] A capacidade de "salvar o dia" depende da noiva ser capaz de se fazer ser afetada da maneira certa, ou pelo menos ser capaz de persuadir as outras pessoas de que está sendo afetada da maneira certa. Corrigir nossos sentimentos é desafetar-se de um afeto anterior: a noiva torna-se feliz impedindo-se de ser infeliz. Aprendemos com esse exemplo que é possível não habitar plenamente a própria felicidade, ou mesmo alienar-se da própria felicidade, se o afeto anterior permanecer vivo, persistindo como algo mais do que 
apenas memória, ou se a própria necessidade de ter que se fazer sentir de uma certa maneira nos inquietar.

Você não consegue sempre fechar a lacuna entre como você se sente e como deveria se sentir. Por trás da nitidez desse "não consegue" está um mundo de possibilidades. $\mathrm{O}$ ativismo atua a partir dessa lacuna, abrindo-a, afrouxando-a? Não fechar a lacuna entre o que você sente e o que deveria sentir pode começar como ou com uma sensação de decepção. A decepção pode envolver uma narrativa ansiosa de duvidar de si mesma (por que não fico feliz com isso; o que há de errado comigo?), ou uma narrativa de raiva, onde ao objeto que "deveria" nos fazer felizes é atribuída a causa da decepção. Sua raiva pode ser dirigida contra o objeto, ou transbordar para aqueles que lhe prometeram felicidade por meio da elevação de tais objetos como bons. Tornamo-nos estranhas, ou alienígenas afetivas, em tais momentos.

Alienígenas afetivas são pessoas que experimentam afetos alienígenas. Você é destituída do seu assento pela mesa da felicidade. Se você perder seu assento, o que acontece? 0 ativismo é frequentemente uma questão de assentos. A palavra "dissidência", por exemplo, deriva do latim dis - "aparte" + sedere "sentar". Dissidente é quem que se senta à parte. Ou dissidente é quem seria destituída ao ocupar um lugar à mesa: seu assento é o local de desacordo. Em Queer Phenomenology, eu estava obcecada demais pelas mesas para notar a esquisitice da cadeira, que era queer. Mas cheguei a sugerir que, se começarmos com o corpo que perde seu assento, o mundo que descrevermos pode ser bem diferente. [3]

\section{Estraga-prazeres}

Ser expulsa pela mesa da felicidade pode ameaçar não apenas aquela mesa, mas o que se reúne em torno dela, o que se reúne sobre ela. Quando você perde seu assento, você pode até atrapalhar quem está, quem deseja mais do que qualquer coisa manter seu assento. Ameaçar a perda do assento pode ser estragar o prazer das pessoas que estão sentadas. Como reconhecemos bem a figura da feminista 
estraga-prazeres! Como ela faz sentido! Levemos a sério a figura da feminista estraga-prazeres. Um projeto feminista poderia ser o de devolver à estragaprazeres a sua voz. Embora ouvir feministas como estraga-prazeres possa ser uma forma de dispensá-las, existe uma agência que essa dispensação, ironicamente, revela. Podemos responder à acusação com um "sim".

A figura da estraga-prazeres feminista faz sentido se a colocarmos no contexto das críticas feministas da felicidade, de como a felicidade é usada para justificar as normas sociais como bens sociais (um bem social é o que causa a felicidade, se a felicidade é entendida como o que é bom). Como Simone de Beauvoir descreveu tão astutamente "é sempre fácil declarar feliz a situação que se lhe quer impor [aos outros]." [4] Não concordar em ficar no lugar desse desejo pode significar recusar a felicidade desejada. Estar envolvida no ativismo político é, portanto, estar envolvida na luta contra a felicidade. Mesmo que estejamos lutando por coisas diferentes, mesmo que os mundos que queremos criar sejam diferentes, talvez possamos compartilhar o que enfrentamos. Nossos arquivos ativistas são, portanto, arquivos infelizes. Basta pensar no trabalho de crítica que está atrás de nós: críticas feministas à figura da "dona de casa feliz"; críticas negras ao mito do "escravo feliz"; críticas queer da sentimentalização da heterossexualidade como "paraíso doméstico". A luta em torno da felicidade fornece o horizonte no qual as reivindicações políticas são feitas. Nós herdamos esse horizonte.

Dispor-se a ir contra uma ordem social, que é protegida como uma ordem moral, uma ordem de felicidade, é dispor-se a causar infelicidade, mesmo se a infelicidade não for a sua causa. Dispor-se a causar infelicidade pode tratar de como vivemos a vida individual (não escolher "o caminho certo" é interpretável como desistir da felicidade que, presume-se, resulta desse caminho). As respostas parentais à prole sair do armário, por exemplo, podem tomar a forma explícita não de estarem infelizes por ela ou ela ser queer, mas de estarem infelizes por ela ser infeliz. [5] Mesmo que você não queira causar a infelicidade de quem ama, uma vida queer pode significar viver com essa infelicidade. Dispor-se a causar 


\section{DOSSIE}

infelicidade também pode ser a maneira como nos envolvemos na luta coletiva, ao trabalharmos com e através de outras pessoas que compartilham nossos pontos de alienação. Aqueles que são depostos das mesas da felicidade podem se encontrar.

Então, sim, levemos a sério a figura da feminista estraga-prazeres. A feminista estraga o prazer de outras pessoas apontando momentos de sexismo? $\mathrm{Ou}$ ela expõe os sentimentos negativos que ficam escondidos, deslocados ou negados sob sinais públicos de alegria? 0 sentimento negativo entra na sala quando alguém expressa raiva sobre alguma coisa, ou a raiva poderia ser o momento em que os sentimentos negativos que circulam através de objetos são trazidos à tona de certa maneira? A figura feminista "na sala", portanto, "bota os outros para baixo", não apenas por falar sobre tópicos infelizes como o sexismo, mas por expor como a felicidade é mantida apagando os sinais de discordância. As feministas, de fato, estragam o prazer em certo sentido: elas perturbam a própria fantasia de que a felicidade pode ser encontrada em certos lugares. Matar uma fantasia pode ainda matar um sentimento. Não é apenas que as feministas podem não ser afetadas positivamente pelo que supostamente causa a felicidade, mas também que nosso fracasso em ser feliz é lido como uma sabotagem da felicidade das outras pessoas.

Podemos considerar a relação entre a negatividade da figura da feminista estraga-prazeres e como certos corpos são "recebidos" como sendo negativos. Marilyn Frye defende que a opressão envolve a exigência de que você mostre sinais de estar feliz com a situação em que se encontra. Ela afirma, "é frequentemente exigido das pessoas oprimidas que sorriamos e sejamos alegres. Se obedecermos, mostramos nossa docilidade e nossa aquiescência em nossa situação." Ser oprimida exige que você dê sinais de felicidade, como sinais de ser ou de ter sido ajustada. Para Frye, "qualquer coisa menos o semblante mais ensolarado nos expõe a sermos percebidas como mesquinhas, amargas, raivosas ou perigosas". [6]

Ser reconhecida como feminista é ser atribuída a uma categoria difícil e a uma categoria de dificuldade. Você é "lida de antemão" como alguém de "difícil convivência" quando se autodenomina feminista. Você tem que mostrar que não é 


\section{DOSSIE}

difícil, dando mostras de boa vontade e felicidade. Frye faz alusão a essas experiências quando descreve como: "isso significa, no mínimo, que podemos ser consideradas 'difíceis' ou desagradáveis de trabalhar, o que é suficiente para custar o sustento." [7] Também podemos testemunhar um investimento na infelicidade feminista (o mito de que as feministas estragam o prazer dos outros porque não têm prazer). Há um desejo de acreditar que as mulheres se tornam feministas porque são infelizes. Esse desejo funciona como uma defesa da felicidade contra a crítica feminista. Isso não quer dizer que as feministas não possam ser infelizes; tornar-se feminista pode significar uma tomada de consciência de quanto há com que ficar infeliz. A consciência feminista pode ser entendida como consciência da infelicidade, uma consciência possibilitada pela recusa em virar-se para o outro lado. Meu ponto aqui é que as feministas são lidas como infelizes, de modo que situações de conflito, violência e poder são lidas como sendo derivadas da infelicidade das feministas, em vez de serem o motivo da infelicidade das feministas.

As lutas políticas podem ocorrer em torno das causas da infelicidade. Precisamos atribuir uma história à infelicidade. Precisamos ouvir na infelicidade mais do que a negação do "in-". A história da palavra "infeliz" pode nos ensinar sobre a infelicidade da história da felicidade. Em seus primeiros usos, infeliz significava causar infortúnios ou problemas. Só mais tarde passou a significar sentir-se infeliz, no sentido de miserável ou triste. Podemos aprender com a rapidez da tradução de causar infelicidade a ser descrita como infeliz. Precisamos aprender.

A palavra "wretched" [miserável], em inglês, tem sua própria genealogia, vinda de wretch, significando uma pessoa estranha, exilada, banida. Wretched no sentido de "pessoa vil e desprezível" foi desenvolvida no Inglês Antigo e se diz que reflete "o estado lamentável da pessoa rejeitada." Podemos reescrever a história da felicidade do ponto de vista do wretch, da pessoa rejeitada? Se escutássemos quem é considerado miserável, talvez a sua miséria não lhe pertencesse mais. A tristeza da estranha pode nos dar uma perspectiva diferente sobre a felicidade não porque 
nos ensina como é ou deve ser, ser uma estranha, mas porque pode tornar-nos estranhas à própria felicidade do familiar.

A fenomenologia nos ajuda a explorar como o familiar é aquilo que não é revelado. Uma fenomenologia queer mostra como o familiar não é revelado para quem pode habitá-lo. Para pessoas queer e outras figuras Outras, o familiar é revelado para você, porque você não o habita. Estar "alienada de" pode ser o que permite uma "consciência de". É por isso que ser uma estraga-prazeres pode ser um projeto de conhecimento, um projeto de criação de mundo.

\section{Mesas Feministas}

Uma chamada feminista pode ser uma chamada para a raiva, para desenvolver um senso de raiva sobre as injustiças coletivas. E, no entanto, é importante que não transformemos a emoção feminista em um local de verdade: como se fosse sempre nítido ou evidente por si só que nossa raiva está certa. Quando a raiva se torna justa, pode ser opressiva; presumir que a raiva nos torna certas pode ser errado. Sabemos com que facilidade uma política da felicidade pode ser substituída por uma política da raiva: a presunção de um direito à felicidade pode se transformar muito rapidamente em raiva dirigida a outras pessoas (imigrantes, estrangeiras, estranhas) que tomaram a felicidade considerada "por direito" a ser nossa. É precisamente que não podemos nos defender contra esse uso defensivo da emoção que é o meu ponto. As emoções nem sempre são justas, mesmo aquelas que parecem adquirir força na ou a partir de uma experiência de injustiça. As emoções feministas são mediadas e opacas; são locais de disputa e devemos persistir em disputa com elas. [8]

Afinal, os espaços feministas são espaços emocionais, nos quais a experiência da solidariedade dificilmente é exaustiva. Como feministas, temos nossas próprias mesas. Se somos depostas da mesa da família, isso não significa necessariamente que estejamos sentadas juntas. Podemos colocar a figura da feminista estraga-prazeres ao lado da figura da mulher negra raivosa, tão bem explorada por escritoras feministas negras como Audre Lorde [9] e bell hooks [10]. 
A mulher negra raivosa pode ser descrita como uma estraga-prazeres; ela pode até estragar o prazer feminista, por exemplo, apontando formas de racismo dentro de políticas feministas. Ela pode nem precisar fazer tais afirmações para estragar o prazer. Ouça a seguinte descrição de bell hooks: "um grupo de ativistas feministas brancas que não se conhecem estão presentes numa reunião para debater a teoria feminista. Sentem que se uniram com base na condição partilhada de mulher, mas a atmosfera mudará visivelmente assim que uma mulher negra entrar na sala. As mulheres brancas ficarão tensas, deixarão de estar relaxadas e num ambiente comemorativo."[11]

Não é apenas que os sentimentos estão "em tensão", mas que a tensão está localizada num lugar: ao ser sentida por alguns corpos, é atribuída como sendo causada por outro corpo, que passa a ser sentido como separado do grupo, atrapalhando sua fruição e solidariedade. Ao corpo não branco é atribuído a causa da tensão, que também é a perda de uma atmosfera compartilhada. Como feminista não branca você nem precisa dizer nada para causar tensão! A mera proximidade de alguns corpos envolve uma conversão afetiva. Aprendemos com esse exemplo como as histórias se condensam na própria intangibilidade de uma atmosfera, ou na tangibilidade dos corpos que parecem atrapalhar. As atmosferas podem se tornar compartilhadas se houver acordo sobre onde localizamos os pontos de tensão.

Uma história pode ser preservada na própria complicação de uma situação. Falar com raiva como uma mulher negra é, então, confirmar sua posição como a causa da tensão; sua raiva é o que ameaça o vínculo social. Como descreve Audre Lorde: "Quando mulheres de $\operatorname{cor}^{2}$ se manifestam sobre a raiva que permeia boa parte dos nossos contatos com as mulheres brancas, com frequência nos dizem que estamos 'criando um clima de impotência, 'impedindo as mulheres brancas de superarem a culpa' ou 'dificultando a comunicação e a ação baseadas na

\footnotetext{
2 Embora na tradução desse texto eu tenha optado pelo termo "mulheres não brancas" para referir a "women of color", a tradução oficial do livro de Audre Lorde, feita por Stephanie Borges, utiliza o termo "mulheres de cor". Como era uma citação direta, usei a tradução já existente.
} 
confiança'”[12] A exposição da violência torna-se a origem da violência. A mulher negra deve abandonar sua raiva para que a mulher branca siga em frente.

A figura da mulher negra raivosa é uma figura fantasiosa que produz seus próprios efeitos. Argumentos razoáveis e ponderados são descartados como raiva (que, naturalmente, esvazia a raiva de sua própria razão), o que dá raiva, de modo que sua resposta passa a ser lida como a confirmação da evidência de que você não está apenas com raiva, mas também pouco sensata! Para explicar isso de outra forma, a raiva das feministas negras é atribuída. Você pode estar com raiva pelo fato que o racismo e o sexismo diminuem as opções de vida para mulheres de cor. Sua raiva é um juízo de que algo está errado. Mas, ao ser ouvida como raivosa, sua fala é interpretada como motivada pela raiva. Sua raiva é lida como não atribuída a algo, como se você fosse contra x porque está com raiva, em vez de estar com raiva porque é contra $\mathrm{x}$. Você fica com raiva da injustiça de ser ouvida como motivada pela raiva, o que torna mais difícil separar-se do objeto de sua raiva. Você se enreda com o motivo de sua raiva, porque tem raiva de como a enredaram em sua raiva. Ao zangar-se com esse enredamento, você confirma o compromisso deles com a sua raiva como a verdade "por trás" do seu discurso, que acaba por bloquear sua raiva, impedindo que ela chegue à compreensão da outra pessoa. Você é bloqueada por não conseguir chegar a se fazer entender.

Alguns corpos tornam-se pontos de bloqueio, pontos onde a comunicação harmoniosa para. Considere o maravilhoso poema em prosa de Ama Ata Aidoo, Our Sister Killjoy [Nossa Irmã Estraga-Prazeres], onde a narradora Sissie, enquanto mulher negra, precisa trabalhar para sustentar o conforto dos outros. Num avião, uma aeromoça branca a convida a se sentar no banco de trás com "suas amigas", duas pessoas negras que ela não conhece. Ela está prestes a dizer que não as conhece e hesita. "Mas se recusar a se juntar a elas teria criado uma situação embaraçosa, não é? Considerando também que, além da educação obviamente civilizada da aeromoça, ela fora treinada para ver o conforto de todos os seus passageiros." [13] 
0 poder fala aqui, neste momento de hesitação. Você colabora? O que significa não colaborar? Criar estranheza é para ser lida como sendo estranha. Manter o conforto público requer que certos corpos "colaborem". Recusar-se a colaborar, recusar o lugar em que você está colocada, é ser vista como causadora de problemas, como deixando outras pessoas desconfortáveis. Há uma disputa política sobre como atribuímos bons e maus sentimentos, que hesita em torno da questão aparentemente simples de quem apresenta quais sentimentos a quem. Os sentimentos podem ficar presos a certos corpos da mesma maneira que descrevemos espaços, situações, dramas. E os corpos podem ficar presos, dependendo dos sentimentos aos quais estão associados.

\section{Atrapalhando}

Uma estraga-prazeres: aquela que atrapalha a felicidade das outras pessoas. Ou apenas aquela que está no caminho - você pode estar no caminho de qualquer coisa, se já for percebida como estando no caminho. A sua mera chegada a uma sala é uma lembrança de histórias que "atrapalham" a ocupação daquela sala. Quantas histórias feministas são sobre salas, sobre quem as ocupa, sobre abrir espaço? Quando chegar é atrapalhar, o que acontece, o que você faz? A figura da estragaprazeres poderia ser repensada em termos de políticas da voluntariosidade. Sugeri anteriormente que um arquivo ativista é um arquivo da infelicidade, moldado pelas lutas de quem se dispõe a lutar contra a felicidade. Podemos redescrever essa luta em termos de quem se voluntaria a ser voluntariosa. Um arquivo da infelicidade é um arquivo da voluntariosidade.

Voltemos: ouçamos o que e quem está atrás de nós. Alice Walker descreve uma "mulherista" da seguinte maneira: "Uma feminista negra ou feminista nãobranca ... Geralmente referindo-se a um comportamento ultrajante, audacioso, corajoso ou voluntarioso. Querendo saber mais e em maior profundidade do que é considerado 'bom' para alguém... Responsável. No comando. Séria." [14] Julia Penelope descreve o lesbianismo como voluntariosidade: "A lésbica se levanta contra o mundo criado pela imaginação masculina. Que voluntariosidade 
possuímos quando reivindicamos nossas vidas!" [15] O feminismo radical de Marilyn Frye usa o adjetivo voluntariosa: "A criação voluntariosa de um novo significado, novos locais de significado e novas maneiras de ser e estar, juntas, no mundo, parece ser nestes tempos mortalmente perigosos, a melhor esperança que temos." [16 ] Voluntariosidade como audácia, voluntariosidade como oposição, voluntariosidade como criatividade.

Podemos entender como a voluntariosidade aparece, se considerarmos uma definição típica de voluntariosidade: "afirmar ou dispor-se a afirmar a própria vontade contra a persuasão, instrução ou comando; governada pela vontade sem levar em conta a razão; determinada a seguir seu próprio caminho; obstinadamente auto-determinada ou perversa" (Oxford English Dictionary). Ser chamada de obstinada ou perversa porque não é persuadida pela razão das outras pessoas? Isso é familiar para você? Você já ouviu isso antes? Quando você é acusada de voluntariosidade, é como se sua existência fosse uma insistência em existir, uma recusa em abrir o caminho, em abrir mão, em abrir mão de seu caminho. Pode o motivo pelo qual somos acusadas se tornar uma carga, uma responsabilidade no sentido de Alice Walker, uma forma de encarregar-se? Se formos acusadas de voluntariosidade, podemos aceitar e mobilizar essa carga.

Precisamos nos tornar voluntariosas, talvez, para continuar seguindo o caminho que estamos seguindo, se o caminho que se está seguindo for percebido como "o caminho errado". Todas nós conhecemos a experiência de "seguir o caminho errado" em meio à multidão. Todo mundo parece estar indo na direção oposta à que você está indo. Ninguém precisa te empurrar ou te atropelar para que você sinta o ímpeto coletivo da multidão como um empurrão e um atropelamento. Para continuar, você precisa se esforçar mais do que qualquer uma das pessoas que estão indo no caminho certo. 0 corpo "no caminho errado" é aquele que é percebido como "no caminho" da vontade que se adquire como ímpeto. Para alguns corpos, a mera persistência, "continuar com firmeza", requer um grande esforço, um esforço que pode parecer para outros como teimosia ou obstinação, como insistência em ir contra o corrente. Você precisa se tornar insistente para ir 
contra a corrente; você é julgada como estando contra a corrente porque é insistente. Um paradoxo da vida: você precisa se tornar o que é julgada ser.

É crucial não presumirmos que a voluntariosidade se refere simplesmente a figuras solitárias que vão contra a maré do social. Ao mesmo tempo, podemos notar como o social pode ser experimentado como uma força: você sente uma força mais diretamente quando tenta resisti-la. É a experiência do "ir contra" que se nomeia na voluntariosidade, razão pela qual uma política voluntariosa precisa ser uma política coletiva. 0 coletivo aqui não é assumido como uma base. Em vez disso, a voluntariosidade é uma reunião de quem luta por uma base diferente para a existência. Você precisa de apoio quando não está indo na direção em que as coisas estão fluindo. É por isso que penso numa política queer feminista como uma política de mesas: as mesas dão suporte a reuniões, e precisamos de suporte quando vivemos nossas vidas de maneiras que outras pessoas percebem como sendo teimosas ou obstinadas.

Um fluxo é um efeito de corpos que estão indo na mesma direção. Ir é também reunir. Um fluxo pode ser o efeito de reuniões de todos os tipos: reuniões de mesas, por exemplo, como objetos de parentesco que sustentam reuniões humanas. Quantas vezes já tive a experiência de ficar à espera de serviço numa mesa quando um casal heterossexual entra na sala e é atendido imediatamente! Para algumas pessoas, é preciso tornar-se insistente para ser o destinatária de uma ação social, talvez seja necessário anunciar sua presença, acenar com o braço e dizer: "Aqui estou!" Para outras pessoas, basta aparecer porque já lhes foi dado um lugar à mesa antes mesmo de ocupá-lo. A voluntariosidade descreve as consequências desiguais dessa diferenciação.

Uma atribuição da voluntariosidade envolve a atribuição de afetos negativos àqueles corpos que atrapalham, aqueles corpos que "vão contra a corrente" no caminho que estão indo. A atribuição da voluntariosidade é, portanto, efetivamente uma acusação de estragar o prazer. As conversas também são fluxos; estão saturadas. Ouvimos essa saturação como atmosfera. Ser considerada voluntariosa é ser quem "estraga a atmosfera." Uma colega me diz que ela só 
precisa abrir a boca nas reuniões para ver os olhos virando como se dissessem: "ih, começou". Minha experiência como filha feminista numa família convencional me ensinou muito sobre revirar os olhos. Você já sabe disso. De qualquer maneira que se fale, quem fala como feminista costuma ser vista como "causadora da discussão", como quem está perturbando a fragilidade da paz. Ser voluntariosa é fornecer um ponto de tensão. A voluntariosidade é pegajosa: é uma acusação que cola.

Se ser considerada voluntariosa é ser a causa do problema, então podemos reivindicar essa voluntariosidade como causa política. As histórias feministas queer estão cheias de figuras voluntariosas autodeclaradas. Pense no Clube da Heterodoxia [Heterodoxy Club] que funcionava em Greenwich Village no início do século XX, um clube para mulheres não ortodoxas. Elas se descreveram como "um pequeno bando de mulheres voluntariosas", como Judith Schwarz revela em sua maravilhosa história deste clube. [17] Uma heterodoxia "não está de acordo com as crenças aceitas ou mantém opiniões não ortodoxas". Ser voluntariosa é dispor-se a anunciar sua discordância e sustentar uma discordância. Concretizar uma discordância pode até significar tornar-se desagradável. 0 feminismo, podemos dizer, é a criação de mulheres bastante desagradáveis.

Histórias políticas de greves e de manifestações são histórias de pessoas que se dispõem a colocar seus corpos no caminho, para transformá-los em pontos de bloqueio que interrompem o fluxo do tráfico humano, bem como o fluxo mais amplo de uma economia. Quando a voluntariosidade se torna um estilo de política, significa não apenas dispor-se a não acompanhar o fluxo, mas também dispor-se a causar sua obstrução. Pode-se pensar na greve de fome como a forma mais pura de voluntariosidade: um corpo cuja agência se expressa ao ser reduzido à obstrução, onde a obstrução para outras pessoas é a auto-obstrução, a obstrução da passagem para dentro do corpo. Histórias de voluntariosidade são histórias das pessoas que se dispõem a colocar seus corpos no caminho.

As formas políticas de consciência também podem ser pensadas como voluntariosidade: não apenas é difícil falar sobre o que recuou da vista, mas você 
tem que se dispor a entrar no caminho desse recuo. Um argumento do feminismo de segunda onda (compartilhado pelo marxismo e a política negra) que acho que vale a pena sustentar é o argumento de que a consciência política é conquistada: aumentar a consciência é um aspecto crucial do trabalho político coletivo. Elevar a consciência é difícil porque a consciência é a consciência do que retrocede. Se o ponto de uma retrocesso é que dá a alguns o poder de ocupar espaço (a ocupação é reproduzida pela ocultação dos sinais de ocupação), então aumentar a consciência é uma resistência a uma ocupação.

Veja o exemplo do racismo. Pode ser voluntarioso até mesmo nomear o racismo: como se a conversa sobre divisões fosse o que causa divisão. Dado que o racismo recua da consciência social, parece que quem o "traz à conversa" o está trazendo à existência. Aprendemos que o próprio falar sobre racismo é vivido como uma intrusão da figura da mulher negra raivosa: como se fosse sua raiva pelo racismo que causasse o afastamento feminista. Recuar é voltar ou retirar-se. Conceder é abrir caminho, ceder. Freqüentemente, pessoas não-brancas são solicitadas a ceder ao retrocesso do racismo: somos solicitadas a "abrir caminho", ao permitir que "volte". Não só isso: mais do que isso. Freqüentemente, somos solicitadas a incorporar um compromisso com a diversidade. Somos convidados a sorrir em seus panfletos. O sorriso da diversidade é uma forma de não permitir que o racismo venha à superfície; é uma forma de retrocesso político.

É muito difícil falar sobre racismo, pois o racismo pode operar para censurar a própria evidência de sua existência. As pessoas que falam sobre racismo são, portanto, ouvidas como criadoras em vez de descritoras de um problema. As apostas são realmente muito altas: falar de racismo é ocupar um espaço saturado de tensão. A história é saturação. Uma das conclusões de um projeto de pesquisa em que estive envolvida sobre diversidade foi que, como o racismo satura os espaços cotidianos e institucionais, as pessoas não-brancas frequentemente tomam decisões estratégicas de não usar a linguagem do racismo. [18] Se você já apresenta um problema ou parece "deslocada" nas instituições da branquitude, pode haver "boas razões" para não usar o que é recebido como um vocabulário 
ameaçador. [19] Não falar de racismo pode ser uma forma de habitar os espaços do racismo. Você minimiza a ameaça que já é suavizando sua linguagem e aparência, mantendo o máximo de distância possível da figura da pessoa negra raivosa. Claro, como sabemos, apenas entrar em uma sala pode significar perder essa distância, porque essa figura chega lá antes de você.

Quando você usa a mera linguagem do racismo, você é ouvido como se estivesse "insistindo nisso", como "não desapegando-se". É como se falar sobre racismo fosse o que o fizesse continuar existindo. 0 racismo, portanto, freqüentemente entra nas formas contemporâneas de representação como a representação de uma experiência passada. Veja o filme Driblando o Destino [Bend it Like Beckham] (2002, dir. Gurinder Chada): o filme tem como premissa a liberdade de ser feliz, representada pela liberdade da filha, Jesminder, de fazer o que a faz feliz (no seu caso jogar futebol - sua ideia de felicidade é o que a aproxima de uma ideia nacional de felicidade). A memória racista de seu pai atrapalha sua felicidade. Considere dois discursos que ele faz no filme, o primeiro no início e o último no final:

Quando eu era adolescente em Nairóbi, era o melhor arremessador rápido de críquete da nossa escola. Nosso time até ganhou a Copa Leste-Africana. Mas quando vim para este país, nada. E uns branquelos malditos do clube zombaram do meu turbante e me mandaram embora ... Ela só vai acabar decepcionada como eu.

Quando aqueles malditos jogadores de críquete ingleses me expulsaram do clube como um cachorro, nunca reclamei. Pelo contrário, jurei que nunca mais jogaria. Quem sofreu? Eu. Mas não quero que Jess sofra. Não quero que ela cometa os mesmos erros que seu pai cometeu, aceitando a vida, aceitando as situações. Eu quero que ela lute. E eu quero que ela ganhe.

Na primeira fala, o pai diz que ela não deve jogar para não sofrer como ele. $\mathrm{Na}$ segunda, ele diz que ela deve jogar para não sofrer como ele. 0 desejo implícito em ambas as falas é a evitação do sofrimento da filha, que se expressa nos termos de um desejo que ela não repita o seu próprio sofrimento. A segunda fala sugere que a recusa em jogar um jogo nacional é a "verdade" por trás do sofrimento do 
migrante: você sofre porque não joga o jogo, onde não jogar é interpretado como autoexclusão. Para deixar Jess ser feliz, ele a deixa ir. Por implicação, ele não apenas a está deixando ir, ele também está deixando ir seu próprio sofrimento, a infelicidade causada por aceitar o racismo, como o "ponto" de sua exclusão.

Eu sugeriria que o pai é representado na primeira fala como sendo melancólico: recusando-se a abrir mão de seu sofrimento, incorporando o objeto de sua própria perda. Sua recusa em deixar Jess ir pode ser lida como um sintoma de melancolia: como um apego teimoso à própria ferida. [20] Como ele diz: "quem sofreu? Eu". O mal-estar, portanto, tem origem no migrante que não abre mão do racismo como um roteiro que explica o sofrimento. 0 migrante melancólico se apega aos objetos infelizes da diferença, como o turbante, ou pelo menos a lembrança de ser zombado pelo turbante, como aquilo que o vincula a uma história de racismo. É como se você devesse desapegar-se da dor do racismo, renunciando o racismo como uma forma de lembrar dessa dor. Eu diria até que o racismo torna-se legível como aquilo a que o migrante melancólico está apegado, como um apego à ferida que permite aos migrantes justificar sua recusa em participar do jogo nacional ("os branquelos em seu clube"). Até mesmo lembrar uma experiência de racismo, ou descrever uma experiência como racismo, pode atrapalhar a felicidade dos outros.

A consciência do racismo passa a ser entendida como uma espécie de falsa consciência, como consciência daquilo que já não existe. 0 racismo é enquadrado como uma memória, que, se fosse mantida viva, apenas nos deixaria exaustas. A tarefa da cidadania passa a ser a da conversão: se o racismo é preservado apenas em nossa memória e consciência, então o racismo "iria embora" se nós também o declarássemos como desaparecido. A narrativa implícita aqui não é que "inventamos o racismo", mas que preservamos seu poder de governar a vida social ao não superá-lo. A tarefa moral é, portanto, "superá-lo", como se, quando você o superasse, o racismo deixasse de existir. 


\section{Conclusão: Um manifesto estraga-prazeres}

Audre Lorde nos ensina o quão rápido a liberdade de ser feliz se traduz na liberdade de desviar o olhar do que compromete sua felicidade. [21] A história das críticas feministas à felicidade poderia ser traduzida em um manifesto: Não desvie o olhar disso: não supere isso. Não superar é uma forma de deslealdade. A voluntariosidade é um tipo de deslealdade: pense no apelo de Adrienne Rich para que sejamos desleais à civilização. Nós não superamos, se não tiver ido embora. Nós não somos leais, se for errado. [22] A voluntariosidade pode ser repensada como um estilo de política: uma recusa em desviar o olhar do que já foi ignorado. As pessoas que apontam que o racismo, o sexismo e o heterossexismo são reais são carregadas de voluntariosidade; se recusam a permitir que essas realidades sejam ignoradas.

Até mesmo falar de injustiças, violência, poder e subordinação em um mundo que usa a "feliz diversidade" como tecnologia de descrição social pode significar tornar-se um obstáculo, como quem "atrapalha” a felicidade alheia. Sua fala é ouvida como uma insistência em pontos doloridos, como se você estivesse se agarrando a algo - uma memória individual ou coletiva, uma sensação de uma história inacabada - porque está ferida. As pessoas costumam dizer que a luta política contra o racismo é como bater a cabeça contra uma parede de tijolos. A parede mantém seu lugar, então é você que fica machucada. Talvez precisemos ficar tão sensíveis quanto nossos argumentos. Claro que não é só isso que dizemos ou fazemos. Podemos reconhecer não apenas que não somos a causa da infelicidade que nos foi atribuída, mas também os efeitos de sermos atribuídas como a causa. Podemos falar sobre sermos figuras voluntariosas, feministas estraga-prazeres, mulheres negras raivosas; podemos reivindicar essas figuras; podemos falar sobre as conversas que tivemos nas mesas de jantar ou em seminários ou reuniões. Podemos rir ao reconhecer a familiaridade de habitar aquele lugar, mesmo que não habitemos o mesmo lugar (e não o fazemos). Pode 
haver prazer em estragar o prazer. Estrague o prazer, nós podemos e fazemos. Seja voluntariosa, nós seremos e nós somos.

\section{Notas}

1. Este artigo é dedicado a todas as feministas estraga-prazeres. Vocês sabem quem são!

2. Arlie Russell Hochschild, The Managed Heart: Commercialization of Human Feeling (Berkeley: University of California Press, 2003) 59-61.

3. Sara Ahmed, Queer Phenomenology: Orientations, Objects, Others (Durham, NC: Duke University Press, 2006) 138.

4. Simone de Beauvoir, The Second Sex, trad. por H.M. Parshley (London: Vintage Books, 1997) 28. [O Segundo Sexo, Trad. Sérgio Milliet. Rio de Janeiro: Nova Fronteira, 2019, p. 26.]

5. Ver, por exemplo: Nancy Garden, Annie on My Mind (Nova York: Farrar, Straus \& Giroux, 1982) 191.

6. Marilyn Frye, The Politics of Reality: Essays in Feminist Theory (Trumansburg, Nova York: The Crossing Press, 1983).

7. Frye, 2-3.

8. Para os primeiros trabalhos sobre a emoção feminista, consulte: Alison Jaggar, "Love and Knowledge: Emotion in Feminist Epistemology", em Ann Garry e Marilyn Pearsall (eds.), Women, Knowledge and Reality: Explorations in Feminist Philosophy (Nova York: Routledge , 1996) 166-190; e Elizabeth Spelman, "Anger and Insubordination", em Ann Garry e Marilyn Pearsall (eds.), Women, Knowledge and Reality: Explorations in Feminist Philosophy (Nova York: Routledge, 1989) 263274. Para um argumento importante sobre a necessidade de separar a injustiça da experiência de dor e mágoa, consulte: Lauren Berlant, "The Subject of True Feeling: Pain, Privacy and Politics" em Sara Ahmed, Celia Lury, Jane Kilby, Maureen McNeil e Beverley Skeggs (eds.), Transformations: Thinking Through Feminism (Londres: Routledge, 2000) 33-47. Para uma discussão mais aprofundada sobre feminismo e emoção, consulte o capítulo final, "Anexos Feministas", que considera admiração, esperança e raiva como emoções feministas em: Sara Ahmed, The Cultural Politics of Emotion (Edimburgo: Edinburgh University Press, 2004). 9. Ver Audre Lorde, Sister Outsider: Essays and Speeches (Trumansburg, Nova York: The Crossing Press, 1984). 
10. Ver bell hooks, Feminist Theory: From Margin to Centre (Londres: Pluto Press, 2000). [bell hooks, Teoria feminista: da margem ao centro, trad. Rainer Patriota. São Paulo: Perspectiva, 2019.]

11. hooks, 56. [tradução: p. 44.]

12. Lorde, 131. [Irmã Outsider, trad. Stephanie Borges, Belo Horizonte: Autêntica, p.44]

13. Ama Ata Aidoo, Our Sister Killjoy (Harlow: Longman, 1997) 10.

14. Alice Walker, In Search of Our Mothers Gardens (Phoenix: New Edition, 2005).

15. Julia Penelope, Call Me Lesbian: Lesbian Lives, Lesbian Theory (Berkeley, CA: Crossing Press, 1992) 42.

16. Marily Frye, Willful Virgin: Essays in Feminism, 1976-1992 (Berkeley, CA: Crossing Press, 1992) 9.

17. Judith Schwarz, Radical Feminists of Heterodoxy (Chicago, IL: New Victoria Publishers, 196) 103.

18. Sara Ahmed, Shona Hunter, Sevgi Kilic, Elaine Swan e Lewis Turner, "Race, Diversity and Leadership in the Learning and Skills Sector", (PDF) Relatório não publicado, 2006.

19. Nirmal Puwar, Space Invaders: Race, Gender and "Bodies out of Place" (Oxford: Berg, 2004).

20. Para excelentes discussões sobre a melancolia racial, ver: Anne-Anlin Cheng, The Melancholia of Race: Psychoanalysis, Assimilation and Hidden Grief (Oxford: Oxford University Press, 2001); e David L. Eng e Shinhee Han, "A Dialogue on Racial Melancholia", em David L. Eng e David Kazanjian (eds.) Loss: The Politics of Mourning (Berkeley: University of California Press, 2003) 343-371.

21. Lorde, 76.

22. Adrienne Rich, "Disloyal to Civilization", em Lies, Secrets and Silence (Norton: New York, 1979). 